\title{
A class of easy-to-implement sliding-mode controllers with constant switching frequency for power converters
}

DOI:

10.1109/ISIE.2007.4374687

Link to publication record in Manchester Research Explorer

\section{Citation for published version (APA):}

Cortés, D., Álvarez, J., Navarro-López, E. M., \& Castro, C. (2007). A class of easy-to-implement sliding-mode controllers with constant switching frequency for power converters. In IEEE International Symposium on Industrial Electronics/IEEE Int Symp Ind Electron (pp. 731-735) https://doi.org/10.1109/ISIE.2007.4374687

\section{Published in:}

IEEE International Symposium on Industrial Electronics|IEEE Int Symp Ind Electron

\section{Citing this paper}

Please note that where the full-text provided on Manchester Research Explorer is the Author Accepted Manuscript or Proof version this may differ from the final Published version. If citing, it is advised that you check and use the publisher's definitive version.

\section{General rights}

Copyright and moral rights for the publications made accessible in the Research Explorer are retained by the authors and/or other copyright owners and it is a condition of accessing publications that users recognise and abide by the legal requirements associated with these rights.

\section{Takedown policy}

If you believe that this document breaches copyright please refer to the University of Manchester's Takedown Procedures [http://man.ac.uk/04Y6Bo] or contact uml.scholarlycommunications@manchester.ac.uk providing relevant details, so we can investigate your claim.

\section{OPEN ACCESS}




\section{A class of easy-to-implement sliding-mode controllers with constant switching frequency for power converters}

\author{
Domingo Cortés, Jaime Álvarez \\ CINVESTAV I.P.N. \\ Dpto. de Ing. Eléctrica \\ Av. IPN, 2508, Col. San Pedro Zacatenco \\ 07360 Mexico City, Mexico \\ Email: domingo.cortes@gmail.com \\ jalvarez@cinvestav.mx
}

\author{
Eva M. Navarro-López \\ Univ. de Castilla-la Mancha \\ ETS de Ingenieros Industriales \\ Av. Camilo José Cela s/n \\ 13071 Ciudad Real, Spain \\ Email: navarro.lopez@gmail.com
}

\author{
Christian Castro \\ Instituto Politécnico Nacional \\ ESIME Unidad Zacatenco \\ 07738 Mexico City, Mexico \\ Email: naruto.christian@gmail.com
}

\begin{abstract}
Generally, sliding-mode controllers have to be modified to achieve a constant switching frequency or at least to have an upper limit for it. A family of sliding-mode controllers easy to implement is proposed in this paper. If a controller has the form specified in this paper then it can be implemented using a pulse-width modulator assuring a constant switching frequency, without requiring the control to be modified. The control structure proposed is shown to be feasible by presenting a controller for the boost converter as an example. Simulations and experimental results show that the controller structure proposed has the usual high performance and robustness of sliding-mode controllers. In addition, it has the very convenient features of constant switching frequency and easy implementation.
\end{abstract}

\section{INTRODUCTION}

Sliding-mode control (SMC) has been proven to be effective in a wide range of practical control problems with nonlinear complex dynamics [1]. Such a success is mainly due to the relatively simple design procedure, the good controlled system performance, in addition to the robustness under input perturbations and variations of system dynamic properties.

The key feature of a system exhibiting sliding modes is its discontinuous nature. The sliding motion can be either intrinsic to the system or be introduced in it by means of a discontinuous control. SMC is particularly appropriate for power electronics systems because these are intrinsically discontinuous. This fact has attracted the interest of many power electronics engineers, who have applied SMC to power converters.

SMC design process gives an expression for the switch position in power converters. In the ideal case, the switching frequency is infinity, which obviously can not be achieved. Nevertheless, the higher the switching frequency is, the better the approximation to an ideal sliding mode is. However, due to the characteristics of the actual switch, an upper limit for this switching frequency must be imposed. In many applications, having a constant switching frequency is desirable, but sometimes is mandatory. Due to this fact, methods to limit the switching frequency have been proposed. In Section II, where the SMC design procedure is revisited, these methods are commented.

The problem of achieving a constant switching frequency has been addressed in several works [2]-[8]. Most of these solutions are based on a relation between the SMC and average control. Such a relation arises from the physical meaning of the equivalent control associated with a SMC. This relation is examined in Section II. A different viewpoint of the SMCaverage-control relation is the basis for the class of controllers proposed in this paper given in Section III.

It can be said that, until now, the SMC design for power converters is divided into two steps. First, to design an ideal SMC. Second, to modify it in order to be implemented with a constant switching frequency, or at least with an upper limit in the switching frequency.

In this paper, a class of sliding surfaces that can be easily implemented is proposed in Section III. This class of SMC can be implemented using a pulse-width modulator (PWM) and, hence, with a constant switching frequency. Thus, the designer will know that as long as the SMC has a certain structure, its implementation is straightforward without requiring the control law to be modified.

In Section IV, an example of a controller pertaining to the class proposed in Section III is presented. Simulations and experimental results given for this example show that the controller is easily implemented and yet is robust under load and input voltage variations. Conclusions and future work are given in the last section.

\section{RELATION BETWEEN SLIDING-MODE CONTROLLERS AND AVERAGE CONTROLLERS IN POWER ELECTRONICS}

Power converters can be modeled as:

$$
\dot{x}=f(x)+g(x) u,
$$

where $x \in \mathbb{R}^{n}$ is the system state vector, and it usually consists of inductor currents and capacitor voltages. $f$ and $g$ are 
continuous vector fields and $u \in\{0,1\}$ is the switch position which makes the system discontinuous.

The result of a SMC design procedure is a controller that determines the switch position. Generally, it has the form,

$$
u= \begin{cases}0 & \text { if } \sigma(x, t)<0 \\ 1 & \text { if } \sigma(x, t)>0\end{cases}
$$

Since sliding-mode controllers are intrinsically discontinuous, it is natural to use the discontinuous model for designing these controllers.

If a sliding-mode controller works then, at some time, the system trajectory will evolve on the surface $\sigma=0$. When this happens, the system trajectory is described by,

$$
\dot{x}=f(x)+g(x) u_{e q},
$$

where $u_{e q}$, addressed as the equivalent control, is the solution for $u$ of the equation $\dot{\sigma}=0$. Dynamics described by (3) is valid just in the ideal case of infinity switching frequency. In the more practical case of having a high but limited switching frequency, the system trajectory does not evolve on the surface $\sigma=0$ but in a boundary layer [9]. In this case, (3) can be written as,

$$
\dot{\tilde{x}}=f(\tilde{x})+g(\tilde{x}) u_{e q},
$$

where $\tilde{x}$ is the average of $x$.

Controller (2) can not be implemented directly because, in this case, the frequency will operate in free run, just limited by physical constraints of the switch element. To have a good efficiency and to protect the switch element, among other practical considerations, the switching frequency must be assured to have an upper limit. To this end, an hysteresis band could be used in (2) instead of the sign of $\sigma$. Alternatively, the switch could be assured to be in on (off)-mode for a constant time and modulate the on (off)-time. In some applications, it is highly convenient, and even mandatory, to have a constant switching frequency. The hysteresis band and constant ontime can only lead to a constant switching frequency in the stationary state.

On the other hand, average control is based on the model

$$
\dot{\tilde{x}}=f(\tilde{x})+g(\tilde{x}) d,
$$

where $\tilde{x}$ is the average system state vector, which consists of the average of inductor currents and capacitors voltages; $f$ and $g$ are the same continuous vector fields than those appeared in $(1) ; d \in[0,1]$ is the duty cycle.

The average-controller design process yields to an expression for the duty cycle,

$$
d=\frac{\operatorname{Num}(\tilde{x})}{\operatorname{Den}(\tilde{x})} .
$$

This signal must be passed through a PWM to do the actual switching.

In [9], it is proven that $u_{e q}$ is the average of $u$. Hence, the performance of a sliding-mode controller $u$ should be like the performance of an average controller $d$ provided that $u_{e q}=d$. This idea is proven in [10]. Consequently, it is posible to design a sliding-mode controller like (2) and implement it with a PWM by making $d=u_{e q}$. In this way, a constant switching frequency is achieved (see Fig. 1). This idea is the basis of several works [3], [6], [8], [11], [12]. The problem is that the implementation of $u_{e q}$ is usually far more difficult than $\sigma$. By using the equivalence between $u_{e q}$ and $d$, an alternative method to simplify the sliding-mode controller implementation is proposed in [8]. Instead of using a PWM in order to achieve (6), it could be assured that $\operatorname{Den}(\tilde{x}) u_{e q}=\operatorname{Num}(\tilde{x})$, and therefore, the necessity of a divisor will be eliminated. However, for this purpose, it is necessary that the PWM has a sawtooth with variable amplitude. All these works part from $\sigma$ and find a way to implement it. In the next section, it is found what is the sliding surface associated with an equivalent control $u_{e q}$ obtained in the process of doing this surface a class of easy-to-implement sliding surfaces.

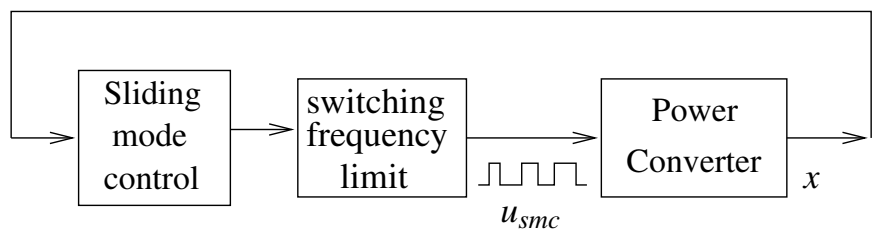

(a) Sliding mode control implementation

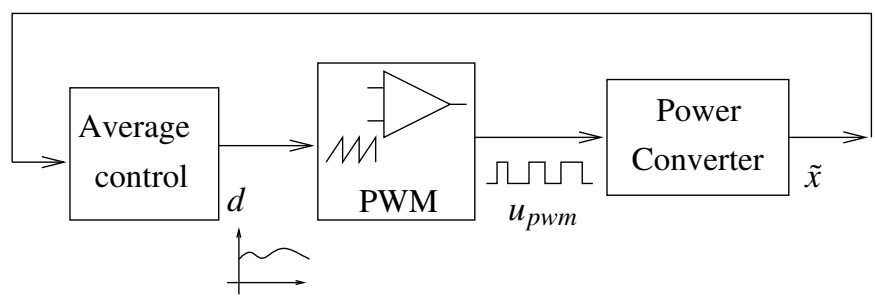

(b) Average control implementation

Fig. 1. Relation between SMC and average controls: If $d=u_{e q}$ then $u_{s m c}$ and $u_{p w m}$ are similar

\section{A FAMILY OF EASY-TO-IMPLEMENT SLIDING-MODE CONTROLLERS}

Let suppose an average controller given by (6) and let pose the question of: what is (if any) the sliding-mode controller that implements (6)? That is, what is the expression for $\sigma$ such that the associated equivalent control is $u_{e q}=d$ ?

From (6), it can be written $\operatorname{Num}(\tilde{x})=\operatorname{Den}(\tilde{x}) d$, that is, $\operatorname{Num}(\tilde{x})-\operatorname{Den}(\tilde{x}) d=0$. The last equation can be written as $\operatorname{Num}(\tilde{x})-\operatorname{Den}(\tilde{x}) u_{e q}=0$. Since $u_{e q}$ is the solution for $u$ of $\dot{\sigma}(x, t)=0$, it can be said that,

$$
\dot{\sigma}=k_{a}(\operatorname{Num}(x)-\operatorname{Den}(x) u(x)),
$$

where $k_{a}$ is a constant. Therefore, from (7),

$$
\sigma=k_{a} \int_{0}^{t}(\operatorname{Num}(x(\tau))-\operatorname{Den}(x(\tau)) u(\tau)) d \tau+k_{b}
$$

where $k_{b}$ is also a constant. Note that $u_{e q}$ is the same, independently of $k_{a}$ and $k_{b}$ values.

It has been shown in this way that: if an average controller $d$ given by (6) corresponds to an equivalent control associated 
with a sliding-mode controller then the sliding surface is given by (8).

Let rename $\phi(x)=\operatorname{Num}(x)$ and set $\operatorname{Den}(x)=1$. Hence, (8) becomes

$$
\sigma=k_{a} \int_{0}^{t}(\phi(x(\tau))-u(\tau)) d \tau+k_{b}
$$

This is an interesting case, because a sliding surface of the form (9) can be easily implemented with a PWM just making $d=\phi(x)$ (see Fig. 1). Therefore, sliding-mode controllers of the form $(2,9)$ are easy to implement with constant switching frequency.

Note that what has been proposed is a structure for sliding surfaces that can be easily implemented with a constant switching frequency via a PWM. For every application, the designer must propose $\phi$ and make sure that $\sigma$ in (9) is indeed a sliding surface, that is, that all the conditions for a sliding mode to exist are accomplished.

In the next section, an example of sliding surfaces of this form is proposed for the boost converter.

\section{EXAMPLE: A SLIDING-MODE CONTROL FOR THE BOOST CONVERTER}

Figure 2 shows a simplified diagram of the boost converter. The circuit objective is to keep a desired constant output voltage regardless of the input voltage and load variations. From the diagram, a linear model can be obtained for each switch position. Combining both models into a single one, the following system is obtained,

$$
\begin{aligned}
& \frac{d}{d t} x_{1}=\frac{V_{i n}}{L}-u \frac{x_{2}}{L}, \\
& \frac{d}{d t} x_{2}=-\frac{x_{2}}{R C}+u \frac{x_{1}}{C},
\end{aligned}
$$

where $x_{1}$ and $x_{2}$ are the inductor current and the capacitor (output) voltage, respectively. $u$ is a binary variable, $u \in\{0,1\}$, which defines the switch position and plays the role of the control input. The inductor $L$, the capacitor $C$, and the source voltage $V_{i n}$ are supposed to be known constants. The resistance $R$ is unknown, but is considered to be constant for analysis purposes.

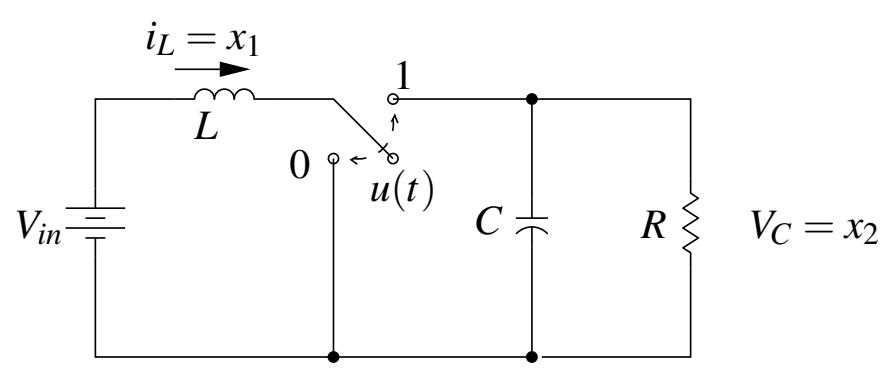

Fig. 2. Schematic diagram of the boost converter.

\begin{tabular}{|c|c|}
\hline$V_{\text {in }}$ & $10 \mathrm{~V}$ \\
$L$ & $2 \mathrm{mH}$ \\
$C$ & $33 \mu \mathrm{Fd}$ \\
$R$ & $25 \Omega$ \\
$V_{\text {ref }}$ & $20 \mathrm{~V}$ \\
\hline
\end{tabular}

TABLE I

PARAMETERS OF THE BOOST CONVERTER

The sliding-mode controller with the surface

$$
\begin{aligned}
\sigma=\int_{0}^{t}\left(G \int_{0}^{\tau}\left(V_{\text {in }}-u(s) x_{2}(s)\right) d s\right. & \\
& +G k_{p}\left(x_{2}(t)-V_{\text {ref }}\right) \\
& \left.+G k_{i} \int_{0}^{\tau}\left(x_{2}(s)-V_{\text {ref }}\right) d s-u(\tau)\right) d \tau,
\end{aligned}
$$

and the switching policy (2) is proposed. The constants $G, k_{p}$ and $k_{i}$ are design parameters of the controller that have to be adjusted to ensure the conditions for a sliding mode to exist. The sliding surface (11) has the form (9) with $k_{a}=1, k_{b}=0$ and,

$$
\begin{aligned}
\phi=G \int_{0}^{\tau}\left(V_{i n}-u(s) x_{2}(s)\right) & d s \\
+G k_{p}( & \left.x_{2}(t)-V_{r e f}\right) \\
& +G k_{i} \int_{0}^{\tau}\left(x_{2}(s)-V_{r e f}\right) d s .
\end{aligned}
$$

Hence, controller $(2,9)$ can be implemented by means of a PWM making $d=\phi(x)$.

The expressión $\phi(x)$ defines a sliding surface by itself, that means that the controller

$$
u= \begin{cases}0 & \text { if } \sigma(x, t)<0 \\ 1 & \text { if } \sigma(x, t)>0 .\end{cases}
$$

is also a sliding-mode controller for system (10). This was proposed in [13] and shown to be also useful for the boost inverter in [14]. The heuristic idea behind proposing $\phi$ as in (12) is the following one: when the system enters in a sliding motion then $\sigma=0$, hence $\dot{\sigma}=0$, and $\phi-u=0$. In the stationary state $u=\bar{u}$, with $\bar{u}$ constant. In this case, $\phi-\bar{u}=0$. This is the condition pursued by the controller proposed in [13].

To illustrate that the controller $(2,11)$ indeed can be implemented using a PWM, the system was simulated in the two forms depicted in Fig. 1. The parameters of the boost converter employed are shown in Table I.

Figure 3 shows the system performance when the controller $(2,11)$ is implemented using an hysteresis band to limit the switching frequency as in Fig. 1(a). To show the robustness of the controller, a sudden load change is introduced at $t=20 \mathrm{mS}$ and at $t=40 \mathrm{mS}$. It can be seen that the controller is highly robust under load variations.

Figure 4 shows a simulation of the system with the same controller but this time, it was implemented like the scheme of Fig. 1(b), that is, using a PWM and making $d=\phi(x)$. The 


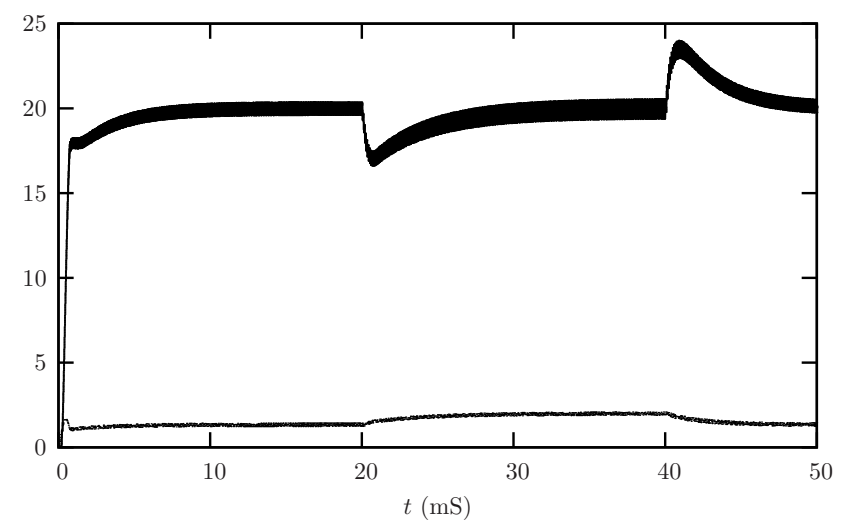

Fig. 3. Simulation of system (10) with the controller $(2,11)$ using an hysteresis band to limit the switching frequency. Top: Output voltage. Bottom: Inductor current

switching frequency was set to $50 \mathrm{KHz}$. It can be seen that both alternatives of implementing the controller have a similar performance. However, the PWM implementation is easier and has the great advantage of having a constant switching frequency.

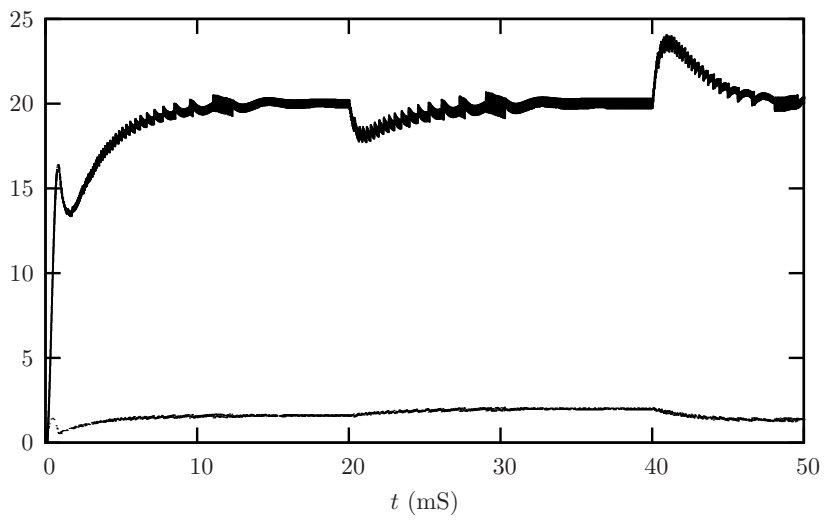

Fig. 4. Simulation of system (10) with the controller $(2,11)$ using a PWM and making $d=\phi$. Top: Output voltage. Bottom: Inductor current

In spite of its apparent complexity, the sliding-mode controller $(2,9,12)$ can be implemented by means of the circuit depicted in Fig. 5. The circuit is rather simple because all signals operations involved in (12) can be carried out with operational amplifiers except the term $V_{\text {in }}-u x_{2}$, where a multiplier is apparently needed. However, it can be noticed from Fig. 2 that the term $V_{i n}-u x_{2}$ actually is the voltage across the inductor. This observation simplifies the circuit. As it is shown in the diagram, the controller only needs the output reference $V_{r e f}$, the output voltage $x_{2}$ and the voltage across the inductor.

The controller has been experimentally evaluated using a PWM and the results are depicted in Figs. 6 and 7. In Fig. 6, the reference is suddenly changed from 0 to $20 \mathrm{~V}$. The output voltage follows this change reasonably fast. The system performance under periodic load variations between open circuit (no load) and $25 \Omega$ is shown in Fig. 7. Note

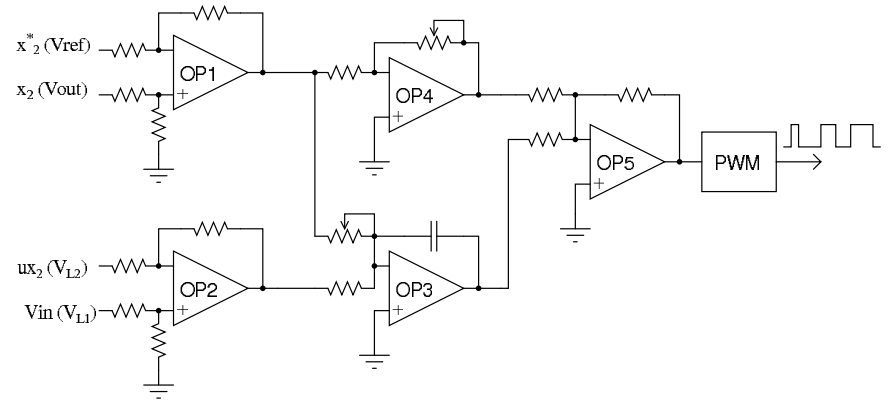

Fig. 5. Diagram of the circuit to implement the controller $(2,9,12)$

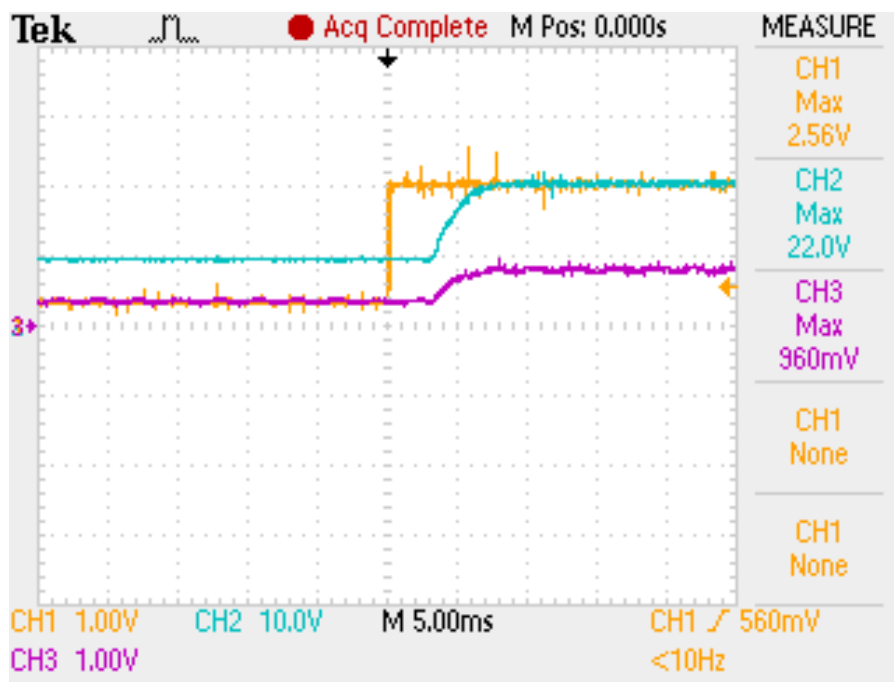

Fig. 6. Performance under sudden reference change.Top: Reference and Output voltage. Bottom: Inductor current.

that variations on the output voltage are very small and after the load changes it returns to its desired value. As it is expected, the inductor current does depend on the load. These experimental results confirm the robustness of the controller, this characteristic was previously observed in simulations.

\section{CONCLUSiOns}

By examining the relation between average control and sliding-mode control, a class of easy-to-implement slidingmode controllers has been proposed in this paper. Since the controllers belonging to this class can be implemented using a pulse-width modulator, they have a constant switching frequency. To show the feasibility of controllers having the structure proposed, an example of a controller of this type for the boost converter has been given. This example shows that the controllers proposed in this paper have the usual high performance and robustness under large parameters variations of sliding-mode controllers. In addition, they have a constant switching frequency and are easy to implement keeping the overall circuit reliability.

To obtain the desired control structure, the sliding surface used in the example has been built using a sliding-mode controller previously proposed. In some sense, it could be 


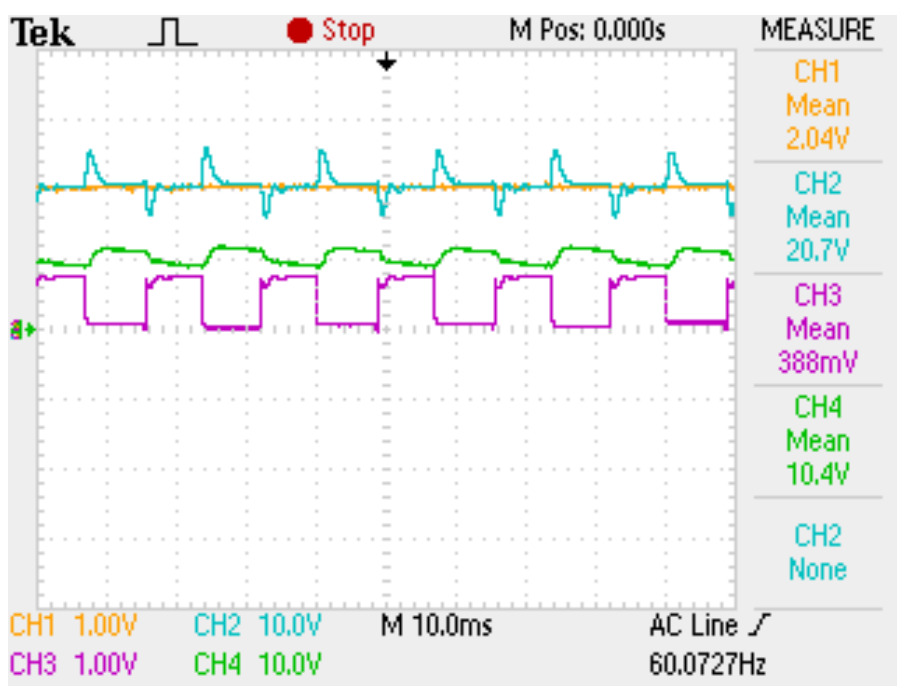

Fig. 7. Performance under load variations.

Top: Reference and Output voltage. Middle: Inductor current. Bottom: Load

said that a sliding surface has been embedded into other sliding surface. This idea of using a sliding surface to build another has been successful for the given example. It would be interesting to know if the same happens for other surfaces and for other converters.

\section{ACKNOWLEDGMENT}

This work was partially supported by CONACYT Mexico under contract 44969. The third author thanks the support of the Ministerio de Educación y Ciencia (MEC) of Spain under Ramón y Cajal contract.

\section{REFERENCES}

[1] V. Utkin, Sliding Modes Control in Electromechanical System. CRC, 1999, iSBN: 0748401164.

[2] P. Mattavelli, L. Rossetto, G. Spiazzi, and P. Tenti, "A general-purpose sliding-mode controller for dc/dc converter applications," in Proceedings of 24th Power Electronics Specialists Conference, 1993, pp. 609-615.

[3] V. M. Nguyen and C. Q. Lee, "Tracking control of buck converter using sliding mode with adaptive hysteresis," in Proceedings of Power Electronics Specialists Conference, 1995, pp. 1086-1093.

[4] R. Ramos, D. Biel, E. Fossas, and F. Guinjoan, "A fixed- frequency quasi-sliding control algorithm: Application to power inverters design by means of fpga implementation," IEEE Trans. on Power Electronics, vol. 18, no. 1, pp. 344-355, Jan. 2003.

[5] S. C. Tan, Y. M. Lai, K. H. Cheung, and C. K. Tse, "On the practical design of a slinding mode voltage controlled buck converter," IEEE Transactions on Power Electronics, vol. 20, no. 2, pp. 425-437, March 2005.

[6] S. C. Tan, Y. M. Lai, C. K. Tse, and K. H. Cheung, "A fixed-frequency pulse-width-modulation based quasisliding mode controller for the buck converter," IEEE Transactions on Power Electronics, vol. 20, no. 6, pp. 1379-1392, November 2005.

[7] S.-C. Tan, Y. M. Lai, and C. K. Tse, "Adaptive feedforward and feedback control schemes for sliding mode controlled power converters," IEEE Transactions on Power Electronics, vol. 21, no. 1, pp. 182-192, January 2006.

[8] —, "Implementation of pulse-width-modulation based sliding mode controller for boost converters," IEEE Power Electronics Letters, vol. 3, no. 4, pp. 130-135, December 2006.

[9] V. Utkin, Sliding Modes in Control and Optimization, ser. Communications and Control Egineering. Springer Verlag, 1991, iSBN: 3540535160 .
[10] H. Sira-Ramírez, "A geometric approach to pulse width modulated control in nonlinear dynamical systems," IEEE Transactions on Automatic Control, vol. 34, no. 3, pp. 184-187, February 1989.

[11] R. Venkataramanan, A. Sabanovic, and S. Cuk, "Sliding mode control of dc-to-dc converters," in IEEE Industrial Electronics Conference IECON. San Francisco CA, USA: IEEE, 1985, pp. 251-258.

[12] V. M. Nguyen and C. Q. Lee, "Indirect implementation of sliding mode control law in buck type converters," in Proceedings of IEEE Applied Power Electronics Conference, 1996, pp. 111-115.

[13] D. Cortes, J. Alvarez, and J. Alvarez, "Robust control of the boost converter," in IEEE Industrial Electronics and Control Applications (ICIECA), Quito, Ecuador, December 2005.

[14] D. Cortes, N. Vazquez, and J. Alvarez, "Robust control of the boost converter," in IEEE Industrial Electronics Conference (IECON), Paris, France, November 2006, pp. 1890-1895. 